\title{
EMPREENDEDORISMO FEMININO E EFFECTUATION: UM ESTUDO NO SETOR DE BELEZA E ESTÉTICA EM CORUMBÁ (MS)
}

Jilseanny Da Silva Magalhães ${ }^{1}$

Roosiley Santos Souza ${ }^{2}$

\footnotetext{
${ }^{1}$ Universidade Federal de Mato Grosso do Sul

${ }^{2}$ Universidade Federal de Mato Grosso do Sul
} 


\section{EMPREENDEDORISMO FEMININO E EFFECTUATION: UM ESTUDO NO SETOR DE BELEZA E ESTÉTICA EM CORUMBÁ (MS)}

Resumo: O presente estudo tem como objetivo evidenciar a lógica Effectuation na criação de negócios por mulheres empreendedoras no ramo de beleza e estética no município de CorumbáMS. Para empreender, segundo a teoria, parte dos meios disponíveis, e das seguintes perguntas, "quem sou?", "o que sei fazer?" e "quem eu conheço?"utilizou-se da pesquisa qualitativa descritiva, um questionário semiestruturado com base na ferramenta effectuation. No que se refere ao processo de amostragem e utilização da amostra, os sujeitos da pesquisa foram as empresárias da cidade. Foi realizada uma abordagem não probabilística por conveniência, de caráter qualitativo, no levantamento dessa população foi utilizada a técnica do Snowball. A partir da análise do conteúdo identificou-se a utilização da lógica Effectuation mesmo que inconscientemente por parte das empresárias participantes. A pesquisa evidenciou a lógica Effectuation.

Palavras-chave: Empreendedorismo. Empreendedorismo Feminino. Teoria Effectuation. Setor Beleza e Estética. Prestação de Serviços.

\section{$1 \quad$ Introdução}

De acordo com Serviço Brasileiro de Apoio às Micro e Empresas (SEBRAE, 2013) nos últimos anos as mulheres ganharam espaço no mercado de trabalho e galgaram posições de poder, conquista que se repete no mundo empreendedor. As empreendedoras estão ganhando visibilidade além da realização pessoal, tornando-se inspiração para que outras possam abrir seu próprio negócio. Nessa vertente, a pesquisa Global Entrepreneurship Monitor (GEM), que tem como escopo compreender o papel do empreendedorismo no desenvolvimento econômico dos países, aponta que em 2018, no Brasil, o percentual de mulheres à frente de negócios em estágio estabelecido foi de $17,2 \%$ e para os homens $23,3 \%$, expondo assim, que os mesmos podem ser diferentes em aspectos como comportamento, características, influências e motivações, o que pode interferir no desenvolvimento, nos modelos de gestão e na competitividade das empresas. Reportando para a cidade locus do estudo - Corumbá/MS, de acordo com dados do Instituto Brasileiro de Geografia e Estatística (IBGE-2014) a cidade possui 108.010 mil habitantes, dos quais, 51.418 mil são mulheres que residem no município. Uma pesquisa realizada pelo SEBRAE em 2018, revelou que entre o número de Microempreendedor Individual (MEI) na cidade,

[...] elas são maioria no total de microempreendedores individuais, e, junto com os homens, colocam o município em quarto lugar com o número de MEIs em Mato Grosso do Sul. Ainda de acordo com a referida pesquisa, elas [...] são atraídas para administrar o próprio negócio por conta da necessidade e, muitas vezes, por conta da maternidade, como afirma SEBRAE MS (2018).

O setor de investimento pelo público feminino é o setor de beleza, no qual existe demanda de mercado e alta rotatividade. As mulheres tornam-se empreendedoras a partir da 
necessidade e/ou oportunidade, da visão de mercado e do interesse em crescer profissionalmente. O ramo de beleza e estética apresenta uma demanda crescente para criação de novos negócios, com isso, principalmente o público feminino, procura especializar-se para trabalhar neste setor.

Uma observação empírica é perceptível a presença feminina generalizada no comércio e serviço da cidade, em especial no setor de beleza e estética. O que torna pertinente entender os motivos pelos quais as mulheres na cidade de Corumbá (MS), decidiram empreender no ramo de beleza e estética na concepção da teoria Effectuation.

\section{Referencial Teórico \\ 2.1.Empreendedorismo}

Empreendedorismo pode-se entender como uma maneira diferenciada de aplicação de recursos, e o aperfeiçoamento de processos organizacionais, de forma criativa pretendendo reduzir os custos e com propósito de alcançar os objetivos. Dentre esses aspectos estão às pessoas responsáveis por esse processo inovador, as quais são denominadas empreendedores, que tem um diferencial e se destacam no mercado.

O empreendedorismo vai além de administrar um negócio, é um modo diferente e inovador de pegar a oportunidade e colocá-la em prática. Conforme, Dornelas (2001) "O empreendedor é aquele que destrói a ordem econômica existente pela introdução de novos produtos e serviços, pela criação de novas formas de organização ou pela exploração de novos recursos materiais".

Para os pesquisadores na área de empreendedorismo Hisrich \& Peter (2004, p. 33), "O papel do empreendedorismo no desenvolvimento econômico envolve mais do que apenas o aumento de produção e renda per capita; envolve iniciar e constituir mudanças na estrutura do negócio e da sociedade".

Dentre as características que tipificam o perfil empreendedor estão à criatividade, a autoconfiança, assumir riscos e detectar as oportunidades de mercado. O empreendedorismo significa resolver um problema ou uma situação, com uma ideia inovadora para o negócio, identificando as oportunidades, agregando valor e tornando o negócio lucrativo.

\subsection{Empreendedorismo e inovação}

O empreendedor é aquele que pensa além das perspectivas de mercado, ele converte uma ideia já existente ou uma nova ideia, em uma inovação de sucesso. Para Schumpeter (1982), houve crescimento econômico por meio da introdução de novos recursos ou na diferenciação de recursos existentes.

Em sua teoria do desenvolvimento, autor diferencia "capitalista" do empresário:

"Mas, qualquer que seja o tipo, alguém só é um empreendedor quando efetivamente levar a cabo novas combinações, e perde esse caráter assim que tiver montado o seu negócio, quando dedicar-se a dirigi-lo, como outras pessoas dirigem seus negócios". (SCHUMPETER, 1982, p. 56).

A autorrealização faz parte das características do empreendedor, onde ele possui o ensejo de ser independente e ter liberdade na profissão. O que diferencia o empreendedor de 
outro empresário é a maneira de lidar com as oportunidades, inovar primeiro que os outros e buscar autonomia pessoal.

Existem três conjuntos que contém algumas características de empreendedores de sucesso, os quais são utilizados como base pelo SEBRAE (2008):

Conjunto de realização: busca de oportunidades: correr riscos calculados; exigências de qualidade e eficiência; persistência e comprometimento.

Conjunto de planejamento: busca de informações; estabelecimento de metas; planejamento e monitoramento.

Conjunto de poder: persuasão e rede de contatos; independência e autoconfiança.

Com base nos conjuntos, vale dizer que não podemos generalizar afirmando que todos os empreendedores chegarão ao sucesso, mas que possamos agir de acordo com atitudes adequadas, e as pessoas com tais características terão mais chance de ser bem-sucedido. sucedido:

No quadro 1 apresenta-se as diferenças entre o empreendedor do empreendedor bem-

Quadro1: Diferenças entre empreendedor e empreendedor bem-sucedido.

\begin{tabular}{|l|l|}
\hline EMPREENDEDORES & \multicolumn{1}{|c|}{ EMPREENDEDORES BEM SUCEDIDOS } \\
\hline Apresentam tenacidade & Possuem experiência de negócio \\
\hline Capacidade de tolerar antiguidade e incerteza & Tem diferenciação no negócio \\
\hline Fazem bom uso dos recursos & Confiam na sua intuição \\
\hline Correm riscos moderados & Trabalhadores incansáveis \\
\hline São imaginativos & Sonhadores realistas (visionários) \\
\hline Volta-se para resultados & Líderes e tem alto envolvimento no negócio \\
\hline
\end{tabular}

Fonte: PICCANÇO et al (2016).

Negócios de empreendedores bem-sucedidos constituem um ambiente inovador, tendo a criatividade como diferencial das demais. A atitude proativa está presente no perfil, fazendo com que o empreendedor obtenha vantagem competitiva, pois ele antecipa, decide, age, empreende, cria e inova, buscando alcançar seus objetivos. Eles estão um passo à frente também quando buscam especializações em áreas de tecnologia e gerenciamento, para que o empreendimento logre sucesso.

\subsection{Empreendedorismo no Brasil}

O indivíduo que possui a capacidade de converter ideia em ação é considerado empreendedor. No livro "Ensino de empreendedorismo no Brasil: panorama, tendências e melhores práticas", um estudo sobre o empreendedorismo no país e dentre vários aspectos destacou-se que,

[...] apesar do crescimento progressivo do ensino em empreendedorismo no Brasil, o mesmo não tem alcançado os empreendedores em potencial de forma efetiva. Potenciais empreendedores podem ser entendidos como pessoas que não empreendem ainda, mas têm a intenção de empreender. (LOPES, 2017, p.246). 
Nessa linha, a pesquisa do CONAJE (2015) onde se conclui que, [...] dos empreendedores em potencial da pesquisa, $43 \%$ não possuem acesso a nenhuma forma de capacitação e $40 \%$ fizeram cursos aleatórios sobre o tema (LOPES, p. 246)

Empreendimentos no Brasil envolvem indivíduos que procuram abrir o próprio negócio para adquirir autonomia financeira, e com isso exploram novas especializações com a intenção de obter vantagem competitiva. Para Lopes (2017),

[...] verificou-se que é necessária à criação de formas mais efetivas para que o ensino de empreendedorismo alcance de fato os interessados. Cabe alertar que o ensino de empreendedorismo pode extrapolar as disciplinas em sala de aula, cursos, palestras, eventos de imersão, entre outros e procurar meios não convencionais, como jogos, para atingir um número cada vez maior (LOPES, 2017 p. 246).

Entende-se que o empreendedorismo se divide em dois fatores de motivação: necessidade e oportunidade. As pessoas buscam alguma forma de obter estabilidade financeira, e empreender é uma das maneiras disponíveis para entrar no mercado, porém, não necessariamente todos chegarão ao sucesso, pois deve saber manter-se no mercado encarando os desafios no mundo empreendedor.

Os considerados empreendedores por oportunidade são aqueles que têm a percepção de negócio no mercado, já os considerados empreendedores por necessidades são os indivíduos que estavam sem opções de emprego ou renda. A revista GEM (2018) mostra através da tabela 1 a seguir o percentual de Taxa de Empreendedorismo Inicial (TEA).

Tabela 1 - Motivação dos empreendedores iniciais: $\operatorname{taxas}^{1}$ (em \%) para oportunidade e necessidade, proporção sobre a TEA ${ }^{2}$ (em \%), estimativas ${ }^{3}$ (em unidades) e razão oportunidade e necessidade - Brasil - 2018.

\begin{tabular}{c|c|c|c}
\hline Motivação & Taxas & Percentual da TEA & Estimativas \\
\hline Oportunidade & 11,0 & 61,8 & 15.107 .684 \\
\hline Necessidade & 6,7 & 37,5 & 9.176 .644 \\
\hline Razão Oportunidade/ Necessidade & & 1,6 & \\
\hline
\end{tabular}

Fonte: GEM Brasil $2018{ }^{1}$ Percentual da população de 18 a 64 anos. ${ }^{2}$ Proporção sobre a TEA: A soma dos valores pode não totalizar $100 \%$ quando houver recusas e/ou respostas ausentes. ${ }^{3}$ Estimativas calculadas a partir de dados da população de 18 a 64 anos para o Brasil em 2018: 136,8 milhões. Fonte: IBGE/Diretoria de Pesquisas. Projeção da população do Brasil e Unidades da Federação por sexo e idade para o período 2000-2030 (ano 2018).

Com base no resultado da pesquisa a oportunidade está acima da necessidade, assim sendo, essas pessoas empreendem a partir de uma ideia pré-existente ou um negócio anterior, onde inovam e criam valor para conquistar o mercado. 


\subsection{EMPREENDEDORISMO FEMININO E SUA RELAÇÃO COM O SETOR DE BELEZA E ESTÉTICA.}

O interesse pela beleza e estética pessoal existe desde a antiguidade, e foi desenvolvendo-se através da modernidade e de estudos e pesquisas no setor. De acordo com Suenaga, et al. (2012),

\footnotetext{
"Para compreender o belo contemporâneo, é preciso voltar aos pensamentos e conceitos que constituem a sociedade. $\mathrm{O}$ conceito do belo e do feio está ligado a questões filosóficas que envolvem muito mais do que o ver, envolve o sentir, o perceber, o aprofundamento da coisa". (SUENAGA, et al.,2012, p. 1)
}

A busca pela "perfeição" persevera, todavia, junto à saúde do corpo e da mente. Dessa forma, a área de beleza e estética vem se mostrando um setor promissor para fazer negócio, levando em conta a visibilidade e a oportunidade de mercado, englobando os cuidados com a beleza, a saúde e o bem-estar, os quais colaboram para a valorização do corpo, da saúde física e psicológica.

Nos tempos atuais esse progresso continua, no entanto, a identidade pessoal exerce um papel importante na realização das necessidades fisiológicas, pois as pessoas procuram na aparência uma realização pessoal. Quando as necessidades são satisfeitas, o bem-estar é conservado e acentuado. Se a necessidade é negligenciada ou frustrada, pode produzir danos que desequilibram o bem-estar biológico ou psicológico.

A partir do momento em que a pessoa tem uma predisposição e ousadia para criatividade, adquire-se a capacidade de empreender, transformando assim, suas ideias em novos negócios.
"Até alguns anos atrás, acreditava-se que o empreendedor era inato, que nascia com um diferencial e era predestinado ao sucesso nos negócios. Pessoas sem essas características eram desencorajadas a empreender" (DORNELAS, 2001 p. 38).

O empreendedorismo feminino está em constante mudança e desenvolvimento, através da percepção no aumento de mulheres no mercado de trabalho. Mulheres são atenciosas e detalhistas, tendo diversas habilidades para atuar em ramos diversificados no mercado de trabalho.

O público feminino está investindo e inovando no setor de beleza, no qual existe demanda de mercado e alta rotatividade. Elas tornam-se empreendedoras a partir da necessidade e/ou oportunidade, da visão de mercado e do interesse em crescer profissionalmente.

A mulher tem capacidade de persuasão e está sempre ligada a vários fatores, pois é capaz de lidar com várias atividades do cotidiano. Elas têm maior preocupação nos detalhes, e nos clientes, conquistando facilmente o público alvo. Com o entendimento de AMORIM e BATISTA (2012, p.6) referenciam ROBBINS (2002), assim:

"As mulheres encorajam a participação, a partilha do poder e da informação e tentam aumentar a autoestima dos seguidores. Preferem liderar pela inclusão 
e recorrem a seu carisma, experiência, contatos e habilidades interpessoais para influenciar os outros". (AMORIM e BATISTA, 2012, p.6)

O SEBRAE tem sido a instituição destaque pela ajuda as mulheres para abrir o próprio negócio, fomentando o empreendedorismo, para que elas possam alcançar seus objetivos, aumentando seus rendimentos e buscando a independência financeira.

Dados de pesquisa em 2019 do SEBRAE diz que: "nos últimos dois anos, a proporção de mulheres empreendedoras que são "chefes de domicílio" passou de $38 \%$ para $45 \%$. Com o avanço, a atividade empreendedora passou a conferir às donas de negócio a principal posição em casa, superando o percentual de mulheres na condição de cônjuge (situação verificada quando a principal renda familiar provém do marido)".

Os dados do SEBRAE ainda mostram que:

"são 9,3 milhões de mulheres à frente de uma empresa no Brasil representando $34 \%$ de todos os donos de negócios do país. As análises feitas pelo_SEBRAE mostram que as mulheres empreendedoras são mais jovens e têm um nível de escolaridade 16\% superior ao dos homens. Entretanto, elas continuam ganhando $22 \%$ menos que os empresários, uma situação que vem se repetindo desde 2015, segundo dados da Pesquisa Nacional por Amostra de Domicílios Contínua (PNADC), do Instituto Brasileiro de Geografia e Estatística (IBGE). Em 2018, os donos de negócio do sexo masculino tiveram um rendimento mensal médio de $\mathrm{R} \$ 2.344$, enquanto que o rendimento das mulheres ficou em R\$1.831"(SEBRAE, 2019).

Ao empreender as mulheres buscam seu espaço no mercado, é uma forma de empoderamento, pois a partir do momento que elas buscam algo melhor para sua vida, adquirem autonomia e geram impacto positivo, reconhecimento.

\subsection{Empreendedorismo feminino em Corumbá-MS}

No Município de Corumbá (MS) é perceptível o crescimento de empreendedores que estão se formalizando através do MEI, o qual traz benefícios e segurança de trabalho. As mulheres empreendem e ao mesmo tempo aproveitam essa oportunidade de estarem perto da família, pois conseguem ter flexibilidade, lidando com fatores diários, obtendo através do seu negócio qualidade de vida.

De acordo com pesquisa executada pelo SEBRAE (2019) em Corumbá MS,

\footnotetext{
“Com mais mulheres a frente dos negócios, as empresas poderão ganhar novos formatos com empreendedoras focadas em resultados, que praticam o desenvolvimento de equipes e parcerias estratégicas de peso, sempre equilibrando qualidade de vida e trabalho, agora é que são elas". SEBRAE (2019).
}

Realidade confirmada pelo infográfico desenvolvido pela Sala do Empreendedor Secretaria Municipal de Indústria, Comércio e Produção Rural, divulgado em 2018, em que demonstrou que o número de mulheres no MEI representava 53\% dos inscritos no ano de 2017. 


\subsection{TEORIA EFFECTUATION}

Effectuation é uma teoria de pensamento da consagrada professora da Darden School of Business, Saras D. Sarasvathy, que é a lógica aplicada pelos empreendedores inconscientemente. Segundo ela, não é a mesma aplicada por executivos, que aplicam principalmente a lógica da causa, que é ensinada nos cursos de administração.

"Enquanto a causação (causation) se baseia na previsão e nos processos em tomar um determinado efeito como dado e se concentra na seleção entre os meios para criar esse efeito, a efetuação (effectuation) é um processo que começa com um conjunto de meios como dado e foca na seleção entre os possíveis efeitos que podem ser criados com esse conjunto de meios (SARASVATHY, 2001)".

Evidenciam-se algumas diferenças entre a lógica causation e effectuation como mostra o quadro 2:

Quadro 2: Causation x Effectuation

\begin{tabular}{|l|l|}
\hline \multicolumn{1}{|c|}{ CAUSATION } & \multicolumn{1}{c|}{ EFFECTUATION } \\
\hline $\begin{array}{l}\text { Focada em traçar estratégias para atingir um objetivo } \\
\text { específico através do conjunto de meios disponíveis; }\end{array}$ & $\begin{array}{l}\text { Parte dos meios disponíveis para estabelecer novos } \\
\text { objetivos; }\end{array}$ \\
\hline $\begin{array}{l}\text { Considera que, se é possível predizer o futuro, é } \\
\text { possível controlá-lo; }\end{array}$ & $\begin{array}{l}\text { Considera que, se puder controlar o futuro, não é } \\
\text { preciso predizê-lo; }\end{array}$ \\
\hline Está envolvida na maior parte das práticas de gestão. & $\begin{array}{l}\text { Está presente nos casos de empreendedorismo de } \\
\text { sucesso. }\end{array}$ \\
\hline
\end{tabular}

Fonte: Adaptado de Saravasthy (2001).

A teoria originaria das pesquisas da Sarasvathy, que reuniu 27 empreendedores experientes e requisitou que trabalhassem em um conjunto de problemas tipicamente encontrados ao empreender, relatando seus pensamentos em voz alta. Ao averiguar o processo de resolução, Sarasvathy apontou que $65 \%$ dos participantes aplicava lógica do efeito em $75 \%$ do tempo.

A metodologia Effectuation parte de meios disponíveis que são definidos a partir das seguintes perguntas:
- Quem eu sou?
- O que sei fazer?
- Quem eu conheço?

À medida que são respondidas de maneira franca, essas perguntas revelam os meios que o empreendedor tem para superar obstáculos e ajudam a alcançar seus objetivos. Sarasvathy (2001) afirma que, embora os empreendedores pretendam gerar um efeito positivo 
com sua iniciativa, o método do efeito não inicia com um objetivo específico. E sim parte de um determinado conjunto de meios, proporcionando que os objetivos apareçam ao longo do tempo, de maneira ocasional, a partir do interesse e da imaginação do empreendedor e das pessoas com quem ele interage.

O novo cenário de empreendedorismo está cada vez mais amplo e com isso surgiram novos estudos sobre inovação empreendedora. De acordo com (Pelogio \& Rocha, 2016):

\begin{abstract}
"O modelo estratégico, dinâmico e interativo, Effectuation, delineia um processo específico de como as organizações podem criar ou fazer sob incerteza. $\mathrm{O}$ processo é orientado à ação, intersubjetivo e, sem usar modelos preditivos, transforma o meio organizacional do empreendedor em novos conjuntos de meios/fins construídos". (PELOGIO \& ROCHA, 2016)
\end{abstract}

Segundo a renomada professora da Darden School of Business Saras Sarasvathy, "A abordagem Effectuation sugere que existam apenas objetivos vagos no início e conexões específicas dos fundadores com os meios/recursos, em relação ao tipo de empresa formada a partir de "quem eu sou", "o que eu sei" e "quem eu conheço" (SARASVATHY, 2001a, 2001b).

A forma como algumas empresas são criadas, está ligada à lógica, de modo a criar o negócio com o recurso disponível, sem seguir um plano de negócio. A concepção de tirar a ideia do papel e colocar em prática segue uma linha de tomada de decisão, que dá certo a partir do momento em que o empreendedor visa uma oportunidade e a executa.

Para aplicar a teoria Effectuation, há cinco princípios implícitos:

\title{
I. PÁSSARO NA MÃO
}

É necessário começar com os meios que possui, sem esperar a oportunidade perfeita ou um planejamento. O empreendedor deve agir a partir daquilo que tem ao seu alcance. É a partir disso que entram as respostas das perguntas básicas: quem você é, o que você sabe e quem você conhece.

\section{PERDA ACESSÍVEL}

Deve-se determinar qual é a perda que se está disposto a tolerar. Então, analisar as oportunidades sempre considerando se a perda envolvida é aceitável. O resultado positivo não é garantido então é essencial estar pronto a assumir riscos, pois o futuro é fundamentalmente imprevisível.

\section{COLCHA DE RETALHOS}

O empreendedor deve desenvolver parcerias com pessoas e organizações que tenham determinação de firmar o compromisso em ajudá-lo a construir o empreendimento - um produto, um serviço, um negócio, dentre outros.

\section{LIMONADA}

O empreendedor também recebe sua parte de limões e, por isso, deve saber lidar com eventualidades. Ou seja, aceitar os imprevistos que aparecem pela trajetória, ajustando-se, em vez de visar apenas os objetivos específicos. 


\section{PILOTO DO AVIÃO}

Refere-se a "controlar o controlável". Nem tudo pode ser controlado, com isso, a teoria envolve atentar-se nas questões que estão dentro do seu alcance de importância.

A metodologia Effectuation dá mais autonomia ao empreendedor, pois ele não estará com um aspecto limitado e sim aberto a novas oportunidades. Portanto, é uma metodologia que evidencia a criatividade empreendedora, possibilitando uma nova visão a inovação.

Aliás, ela favorece o trabalho manual, ou seja, começar o quanto antes, em vez de gastar um tempo excessivo em planejamento. Afinal de contas, dentro dessa lógica, é considerado que o futuro é imprevisível. Logo, a lógica dá o impulso para tirar as ideias do papel, seguindo rumo ao sucesso.

\section{Metodologia}

Consoante aos trabalhos de Acevedo e Nohara (2007), Mattar (2008), Vergara (2012) e Takahashi (2013), está pesquisa se configurou como qualitativa de caráter exploratório e descritivo, pois tem como propósito proporcionar maior familiaridade com o problema, com vistas a torná-lo mais explícito.

Quanto ao caráter da pesquisa, se configura como uma abordagem qualitativa, pois segundo Takahashi (2013):

É, por excelência, multimétodo, constituindo-se numa abordagem que procura compreender os fenômenos humanos e sociais de forma naturalística e interpretativa. Isso significa que os pesquisadores qualitativos estudam as coisas em seus ambientes naturais, tentando entender ou interpretar os fenômenos em termos dos significados que as pessoas the atribuem. (TAKAHASHI,2013, p.36)

Em relação aos objetivos, inicialmente foi realizada a pesquisa exploratória, que segundo Mattar (2008, p.85), visa prover o pesquisador de um maior conhecimento do tema ou problema de pesquisa. Descritiva, visto que "a pesquisa exploratória visa, à priori, acumular informações disponíveis relacionadas a um problema de pesquisa conclusiva, a ser efetuada ou em andamento" (MATTAR, 2008, p. 86). Assim, a pesquisa conclusiva descritiva objetiva "dirigir a pesquisa, por meio de procedimentos formais, para a solução de problemas e, ou, a construção de cursos de ação". (MATTAR, 2008, p. 90).

A pesquisa conclusiva descritiva, realizada nesta pesquisa, ocorreu por meio do Levantamento de Campo "onde se procura dados representativos da população de interesse" (MATTAR, 2008, p. 92). A coleta desses dados foi efetivada através de um roteiro de entrevista semiestruturado desenvolvido pelos autores com base na ferramenta effectuation (adaptado Read e Sarasvathy, 2005. Nakagawa, 2014). De acordo com Cervo \& Bervian (2002), "a entrevista é uma das principais técnicas de coletas de dados e pode ser definida como conversa realizada face a face pelo pesquisador junto ao entrevistado.

No que se refere ao processo de amostragem e utilização da amostra, os sujeitos da pesquisa foram as empresárias da cidade de Corumbá/MS que atuam no setor de beleza e estética. Foi realizada uma abordagem não probabilística por conveniência - "Amostragem não 
probabilística por conveniência: os elementos da população para compor a amostra depende ao menos em parte do julgamento do pesquisador que seleciona membros da população mais acessíveis. (MATTAR, 2008, p.275), onde, Acevedo e Nohara (2007, p.56) afirmam que as pessoas são selecionadas de acordo com a conveniência do pesquisador, ou seja, são os sujeitos que estão ao alcance do investigador. Foi optado por manter o sigilo das empresárias. Dessa forma, cada entrevistada foi referenciada com a letra $\mathrm{E}$ (Entrevistado) em uma sequência cardinal (E1; E2; E3; e assim sucessivamente).

Por ter caráter qualitativo, no levantamento dessa população foi utilizada a técnica do Snowball (Bola de Neve). Segundo a WHA (1994), essa técnica é uma forma de amostra não probabilística utilizada em pesquisas sociais onde os participantes iniciais de um estudo indicam novos participantes que por sua vez indicam novos participantes e assim sucessivamente, até que seja alcançado o objetivo proposto (o "ponto de saturação"). O "ponto de saturação" é atingido quando os novos entrevistados passam a repetir os conteúdos já obtidos em entrevistas anteriores, sem acrescentar novas informações relevantes à pesquisa.

Fundamentado na estrutura da análise qualitativa, Vergara $(2012$, p.7) apresenta a técnica de tratamento de dados da Análise de Conteúdo proposta na perspectiva de Bardin (1977). "A análise de conteúdo pode ser amparada por procedimentos de cunho quantitativo ou qualitativo [...] envolve um conjunto de técnicas de análise dos dados objetivando chegar a um relatório final de pesquisa". (VERGARA, 2012, p.7-8).

Baseado em Vergara (2012, p.10) os dados obtidos em todas as etapas deste trabalho foram avaliados por meio de algumas técnicas da análise de conteúdo que ocorreu por meio da definição do problema da pesquisa; revisão da literatura pertinente e que ofereceu suporte ao estudo; coleta de dados; análise do material coletado de forma qualitativa (confrontando os resultados da pesquisa com a teoria que deu suporte a investigação); formulação da conclusão e elaboração do artigo.

Diante do exposto, foi feita a identificação das empreendedoras, analisou-se o perfil de cada uma, e através da entrevista analisou-se o processo decisório no início do empreendimento e se seguem a lógica effectuation.

\section{Apresentação dos Resultados e análise}

A seguir serão apresentados os dados coletados através da entrevista e respectivas análises fundamenta na teoria do effectuation.

\subsection{PERFIL SOCIOECONÔMICO DAS EMPRESÁRIAS}

No que se refere ao perfil das empresárias participantes, a pesquisa demonstrou que das 06 respondentes a faixa etária entre as respondentes está entre 31 anos e 41 anos, casadas, com ensino médio completo, com faixa salarial individual predominante de até 3 salários mínimos e renda familiar variando de 3 a 5 salários, conforme apresentado no quadro 3: 
Quadro 3 Perfil Socioeconômico

\begin{tabular}{|c|c|c|c|c|c|}
\hline Empreendedoras & Idade & $\begin{array}{l}\text { Estado } \\
\text { Civil } \\
\end{array}$ & $\begin{array}{l}\text { Nível de } \\
\text { Escolaridade }\end{array}$ & $\begin{array}{l}\text { Renda média } \\
\text { familiar }\end{array}$ & $\begin{array}{l}\text { Renda média } \\
\text { individual }\end{array}$ \\
\hline A & $\begin{array}{l}\text { De } 31 \\
\text { a } 40\end{array}$ & Casada & Ensino médio & $\begin{array}{l}\text { Até } 3 \text { salários } \\
\text { (R\$ 2.944,00) }\end{array}$ & $\begin{array}{l}\text { Até } 3 \text { salários } \\
(\mathrm{R} \$ 2.944,00)\end{array}$ \\
\hline B & $\begin{array}{l}\text { Mais } \\
\text { de } 50\end{array}$ & Separada & Ensino médio & $\begin{array}{l}\text { Superior a } 7 \text { salários } \\
(\mathrm{R} \$ 6.986,00)\end{array}$ & $\begin{array}{l}\text { Superior a } 7 \text { salários } \\
(\mathrm{R} \$ 6.986,00)\end{array}$ \\
\hline $\mathrm{C}$ & $\begin{array}{l}\text { De } 31 \\
\text { a } 40\end{array}$ & Casada & Ensino médio & $\begin{array}{l}\text { De } 3 \text { a } 5 \text { salários } \\
(\mathrm{R} \$ 2.944,00 \text { até } \mathrm{R} \$ \\
4.990,00)\end{array}$ & $\begin{array}{l}\text { Até } 3 \text { salários } \\
(\mathrm{R} \$ 2.944,00)\end{array}$ \\
\hline D & $\begin{array}{l}\text { De } 41 \\
\text { a } 50\end{array}$ & Casada & Ensino médio & $\begin{array}{l}\text { De } 5 \text { a } 7 \text { salários } \\
(\mathrm{R} \$ 4.990,00 \text { até } \mathrm{R} \$ \\
6.986,00)\end{array}$ & $\begin{array}{l}\text { De } 3 \text { a } 5 \text { salários } \\
(\mathrm{R} \$ 2.944,00 \text { até } \mathrm{R} \$ \\
4.990,00)\end{array}$ \\
\hline $\mathrm{E}$ & $\begin{array}{l}\text { De } 41 \\
\text { a } 50\end{array}$ & Casada & Graduação & $\begin{array}{l}\text { Até } 3 \text { salários } \\
(\mathrm{R} \$ 2.944,00)\end{array}$ & $\begin{array}{l}\text { Até } 3 \text { salários } \\
(\mathrm{R} \$ 2.944,00)\end{array}$ \\
\hline $\mathrm{F}$ & $\begin{array}{l}\text { De } 21 \\
\text { a } 30\end{array}$ & Solteira & Pós-graduação & $\begin{array}{l}\text { Até } 3 \text { salários } \\
(\mathrm{R} \$ 2.944,00)\end{array}$ & $\begin{array}{l}\text { Até } 3 \text { salários } \\
(\mathrm{R} \$ 2.944,00)\end{array}$ \\
\hline
\end{tabular}

Fonte: Elaborado pelas

Os dados demonstram que a tomada de decisão foi a partir da necessidade de poder contribuir na renda familiar.

A seguir, o quadro 4 foi traçado a descrição do que a empreendedora era quando decidiu empreender, a partir da pergunta da teoria "Quem eu sou?".

Quadro 4 - “Quem eu sou?”

\begin{tabular}{|l|l|l|l|l|l|}
\hline Empreendedora & Origem & Formação & Hobbies/gostos & $\begin{array}{l}\text { Qual era a } \\
\text { situação de } \\
\text { vida }\end{array}$ & $\begin{array}{l}\text { Experiência } \\
\text { profissional }\end{array}$ \\
\hline A & São Luís & $\begin{array}{l}\text { Cursos na área de } \\
\text { cabelos }\end{array}$ & $\begin{array}{l}\text { Yoga, cabelos, } \\
\text { cozinhar }\end{array}$ & $\begin{array}{l}\text { Funcionária } \\
\text { em outro } \\
\text { salão }\end{array}$ & $\begin{array}{l}\text { Salões de } \\
\text { beleza }\end{array}$ \\
\hline B & Paraná & Cursos & Cabelos & $\begin{array}{l}\text { Funcionária } \\
\text { em outro } \\
\text { salão }\end{array}$ & $\begin{array}{l}\text { Salões de } \\
\text { beleza }\end{array}$ \\
\hline C & Corumbá & Curso de estética & $\begin{array}{l}\text { Dona de casa, } \\
\text { estética }\end{array}$ & $\begin{array}{l}\text { Dona de } \\
\text { casa }\end{array}$ & Nenhuma \\
\hline D & Corumbá & $\begin{array}{l}\text { Cursos técnicos e } \\
\text { profissionalizantes }\end{array}$ & $\begin{array}{l}\text { Corrida, } \\
\text { cabelos }\end{array}$ & $\begin{array}{l}\text { Atendente } \\
\text { de livraria }\end{array}$ & Vendas \\
\hline E & Aquidauana & $\begin{array}{l}\text { Curso superior de } \\
\text { cabeleireira }\end{array}$ & $\begin{array}{l}\text { Caminhada, } \\
\text { salão }\end{array}$ & $\begin{array}{l}\text { Vendas de } \\
\text { roupas }\end{array}$ & $\begin{array}{l}\text { Venda e } \\
\text { beleza }\end{array}$ \\
\hline F & Corumbá & $\begin{array}{l}\text { Engenharia } \\
\text { química }\end{array}$ & $\begin{array}{l}\text { Yoga, } \\
\text { plantação }\end{array}$ & $\begin{array}{l}\text { Viajante } \\
\text { cosmáticos } \\
\text { naturais }\end{array}$ \\
\hline
\end{tabular}

Fonte: Elaborado pelas autoras a partir da ferramenta effectuation (adaptado Read e Sarasvathy, 2005. Nakagawa, 2014).

Grande parte das entrevistadas já residiam em Corumbá, eram funcionárias em outros estabelecimentos, e a partir do que já sabiam procuraram especializações para aprimorar seus 
conhecimentos e abrir o próprio negócio. Seguindo com base dos princípios implícitos a partir do "pássaro na mão", as empreendedoras iniciaram a partir dos meios disponíveis e do que tinham ao seu alcance.

Com o passar dos dias, meses ou até anos lidar com eventualidades faz parte do processo de decisões, e o princípio "limonada" mostra como o futuro é imprevisível onde empreendedor ajusta-se focalizando nos objetivos específicos.

No quadro 5 apresenta-se a segunda questão da teoria Effectuation - "O que eu sei"? e foi analisado o que a empreendedora sabia no momento de empreender.

Quadro 5 - "O que eu sei?"

\begin{tabular}{|l|l|l|l|}
\hline Empreendedora & $\begin{array}{l}\text { Quais } \\
\text { competências } \\
\text { tinham? }\end{array}$ & O que podia fazer? & Fez plano de negócio? \\
\hline A & $\begin{array}{l}\text { Cabeleireira, } \\
\text { cozinhar }\end{array}$ & $\begin{array}{l}\text { Abrir um salão com um } \\
\text { novo conceito de beleza } \\
\text { alternativo, voltada para } \\
\text { realçar os fios naturais }\end{array}$ & $\begin{array}{l}\text { "Não, fui me adaptando às } \\
\text { eventualidades..." }\end{array}$ \\
\hline B & Cabeleireira & Criar o próprio salão & $\begin{array}{l}\text { "Não, criei sem conhecer muitas } \\
\text { pessoas...." }\end{array}$ \\
\hline C & $\begin{array}{l}\text { Fazer unhas em } \\
\text { domicílio }\end{array}$ & $\begin{array}{l}\text { Montar o próprio salão de } \\
\text { beleza e estética }\end{array}$ & $\begin{array}{l}\text { "Não, fui aumentando o número de } \\
\text { clientes..." }\end{array}$ \\
\hline E & $\begin{array}{l}\text { Vendas de } \\
\text { cosméticos e } \\
\text { vendas em geral }\end{array}$ & $\begin{array}{l}\text { Criar o salão por } \\
\text { necessidade e poder } \\
\text { cuidar da filha }\end{array}$ & $\begin{array}{l}\text { "Não, participou de projetos sobre } \\
\text { compreendedorismo e capacitações } \\
\text { aperfeiçoamentos..." }\end{array}$ \\
\hline F & $\begin{array}{l}\text { Unhas, depilação, } \\
\text { cabelo, vendas de } \\
\text { roupas }\end{array}$ & $\begin{array}{l}\text { Criar o salão por } \\
\text { necessidade }\end{array}$ & $\begin{array}{l}\text { "Não, comecei atendimentos a } \\
\text { domićlío para aumentar o número de } \\
\text { clientes..." }\end{array}$ \\
\hline $\begin{array}{l}\text { Viagens para } \\
\text { pesquisas, } \\
\text { permacultura, } \\
\text { produtos naturais }\end{array}$ & $\begin{array}{l}\text { Criar um projeto voltado a } \\
\text { produtos de cosmético } \\
\text { naturais }\end{array}$ & $\begin{array}{l}\text { "Não, foram acontecendo várias } \\
\text { coisas que não tinha imaginado..." }\end{array}$ \\
\hline
\end{tabular}

Fonte: Elaborado pelas autoras a partir da ferramenta effectuation (adaptado Read e Sarasvathy, 2005. Nakagawa, 2014).

A partir do momento que decidiram empreender, tiveram que ter em mente uma perda aceitável que poderia vir a ocorrer, se caso acontecesse seria tolerável e a partir disso buscar outros meios, partindo do princípio "perda acessível".

Com a experiência adquirida as empreendedoras buscaram informações, cursos, referências para atuarem no mercado. Elas não fizeram um planejamento em longo prazo ou um plano de negócio complexo, apenas colocaram em pratica a ideia inicial, lidando com as surpresas e expandindo com a incerteza.

$\mathrm{O}$ quadro 6 a mostra quem as empreendedoras conheciam quando decidiram empreender, a partir da pergunta "Quem eu conheço?" 
Quadro 6 - "Quem eu conheço?”

\begin{tabular}{|c|c|c|c|}
\hline Empreendedora & $\begin{array}{l}\text { Quais eram os } \\
\text { principais amigos? }\end{array}$ & $\begin{array}{l}\text { Amigos, colegas e } \\
\text { conhecidos que } \\
\text { apoiavam a ideia }\end{array}$ & $\begin{array}{l}\text { Como podia encontrar as pessoas para } \\
\text { colaborar com seu negócio? }\end{array}$ \\
\hline A & Amiga, sócia & $\begin{array}{l}\text { Amiga, sócia, dona do } \\
\text { estabelecimento } \\
\text { representantes } \\
\text { produtos }\end{array}$ & Redes sociais, boca a boca \\
\hline B & Irmãos & $\begin{array}{l}\text { Família, irmãos e um } \\
\text { amigo da irmã }\end{array}$ & Propaganda, jornais e rádio \\
\hline $\mathrm{C}$ & Sozinha & Sozinha & Através das clientes \\
\hline $\mathrm{D}$ & Ex-marido, amiga & $\begin{array}{l}\text { Ex-marido, amiga, } \\
\text { família, pessoas com } \\
\text { experiência no ramo }\end{array}$ & Ligações, salões \\
\hline $\mathrm{E}$ & Amiga & Amiga & Porta em porta \\
\hline $\mathrm{F}$ & Pais & Pais e amigas & Redes sociais \\
\hline
\end{tabular}

Fonte: Elaborado pelas autoras a partir da ferramenta effectuation (adaptado Read e Sarasvathy, 2005, Nakagawa, 2014).

As empreendedoras iniciaram com os recursos disponíveis com ajuda de stakeholders que para ROCHA e GOLDSCHMI (2010, p. 5), “[...] são os públicos de interesse, grupos ou indivíduos que afetam e são significativamente afetados pelas atividades da organização: clientes, colaboradores, acionistas, fornecedores, distribuidores, imprensa, governo, comunidade entre outros", e conseguiram criar o empreendimento, tal ajuda parte do princípio "colcha de retalhos", onde a busca de parceria é essencial para expandir o negócio.

O empreendedor que segue a linha effectuation, mesmo que inconscientemente, está aberto a eventuais oportunidades, com isso deve-se atentar para questões que estão dentro do seu alcance de importância, colocando em prática seu lado criativo e inovador, o princípio "piloto de avião" evidencia-se nessa questão.

Com a análise dos resultados feita com as respondentes das entrevistas, fica claro que essas mulheres buscaram ser donas do seu próprio negócio, ter independência financeira, necessidade de realização pessoal e poder cuidar dos filhos, todas as perguntas foram respondidas de forma clara e objetiva, e as principais falas em destaque remetem ao preconizado pela teoria norteadora do presente estudo.

\section{CONSIDERAÇÕES FINAIS}

Esta pesquisa está voltada para área do empreendedorismo feminino e a teoria do Effectuation, visto que, atualmente, a mulher tem tido grande destaque por suas crescentes conquistas e, principalmente, por sua notável participação nos novos empreendimentos. E a teoria ainda carece de estudos para a sua compreensão. Deste modo, um campo de pesquisa a ser explorado e entendido, buscando os diversos fatores que influenciaram nesse processo.

A partir da pesquisa bibliográfica realizada e dos dados coletados na pesquisa, identificou-se o perfil socioeconômico e os processos decisórios na criação das empresas de 
mulheres empreendedoras na área de beleza e estética em Corumbá-MS, verificando as evidências da lógica effectuation.

Os principais resultados do perfil socioeconômico desta pesquisa apontam que grande parte das empresárias participantes possuem entre 31 anos e 41 anos, casadas, a maioria apenas com o com ensino médio completo, com faixa salarial individual predominante de até 3 salários mínimos e renda familiar variando de 3 a 5 salários, possuem CNPJ, são naturais de outras cidades $(50 \%)$ vieram para Corumbá devido a mudança da família e as outras (50\%) são naturais da cidade. A formação profissional delas baseadas em cursos na área de estética e beleza, oriundas de outros salões como funcionárias e o que sabiam fazer era trabalhos na área de beleza e estética e a decisão pelo próprio empreendimento ocorreu sem um plano de negócios.

A pesquisa revela que para empreender, basta ter coragem de iniciar o negócio e encarar o mercado. Segundo a teoria, o empreendedor pode começar a partir das perguntas básicas, "quem eu sou", "o que eu sei" e "quem eu conheço" (SARASVATHY, 2001 a, 2001b), as quais as empreendedoras fizeram inconscientemente, como na maioria dos casos.

Ao invés de fazer um plano de negócio ou captar altos recursos, pode-se iniciar com os recursos que possui, colocando em prática suas habilidades, receber ajuda de pessoas e se adaptar as eventualidades com o decorrer do tempo. Para Lopez (2017), "[...] os empreendedores se motivam enquanto procuram e avaliam formas de solucionar os problemas de seus empreendimentos".

O empreendedorismo é uma ferramenta para a mudança social e as mulheres estão cada vez mais encorajadas de ter seu próprio negócio. É perceptível o brilho nos olhos das pessoas que são empreendedoras, e a partir disso trabalham no que sentem satisfação.

A maioria das entrevistadas tiveram apoio da família para iniciarem o negócio e atualmente utilizam como ferramenta de divulgação o "boca-a-boca" e as redes sociais.

Com a análise dos resultados feita com as respondentes das entrevistas, fica claro que essas mulheres buscaram ser donas do seu próprio negócio, ter independência financeira, necessidade de realização pessoal e poder cuidar dos filhos, todas as perguntas foram respondidas de forma clara e objetiva, e as principais falas em destaque remete ao preconizado pela teoria norteadora do trabalho - teoria effectuation. Para estudos futuros sobre o assunto, proporcionando maior clareza sobre a ótica effectuation, que é um assunto de grande relevância à tomada de decisão na criação de negócios. Sugere-se a ampliação dos estudos em outros setores e vertentes de estudos sobre gêneros.

\section{REFERÊNCIAS}

ACEVEDO, Claudia Rosa; NOHARA, Jouliana Jordan. Monografia no curso de Administração: guia completo de conteúdo e forma: inclui normas atualizadas da ABNT, TCC,



AMORIM, Rosane Oliveira1, BATISTA, Luiz Eduardo2-EMPREENDEDORISMO FEMININO: razão do empreendimento (2012).

BARDIN, L. Análise de conteúdo. Lisboa: Edições 70, 1977 
CERVO, A. L. BERVIAN, P. A. Metodologia científica. 5.ed. São Paulo: Prentice Hall, 2002.

DORNELAS, JOSÉ CARLOS ASSIS (2001), EMPREENDEDORISMO, transformando ideias em negócios. Editora, CAMPUS.

GIL, Antonio Carlos. Como elaborar projetos de pesquisa. 4. ed. São Paulo: Atlas, 2007.

GEM.

Relatório

Executivo.

Disponível

em:

http://www.ibqp.org.br/upload/tiny_mce/Download/GEM_2018_Relatorio_Executivo_Brasil. pdf> Acesso em: 13/10/2019.

HISRICH, R. D.; PETER, M. P. Empreendedorismo. Porto Alegre: Bookman. 2004

IBGE Instituto Brasileiro de Geografia e Estatística 2014- Disponível em: http://www.ibge.gov.br/home/estatistica/populacao/estimativa2014/estimativa_tcu.shtm Acesso em 14 de maio de 2019

LOPES, ROSE MARY ALMEIDA, Ensino de Empreendedorismo no Brasil: panorama, Tendências e Melhores Práticas [ et al]; organizado por Rose Mary Lopes - Rio de Janeiro: Alta Books, 2017. 352 p. : il.

MATTAR, Fauze Najib. Pesquisa de Marketing: Metodologia e Planejamento. $6^{\text {a }}$. Ed. São Paulo: Atlas, 2008.

NAKAGAWA, Marcelo. Ferramenta: effectuation para não empreendedores. Estratégia e gestão. Ano xxx

PELOGIO, Emanuelly Alves et al. Criação de Empresas à Luz do Modelo de Decisão Effectuation: Um Estudo com Mulheres Empreendedoras de um Município do Nordeste Brasileiro. REA UFSM - Rev. Adm. UFSM, Santa Maria, [S.I.], v. 9, n. 4. p. 644-663, set. 2016.

PICANÇO, Fabiana Cristina de Azevedo; GALVÃO, Margareth Soares; CARNEIRO, Reginaldo Aparecido; PERIOTTO, Tânia Regina Corredato. EMPREENDEDORISMO, coletânea de artigos. (2016, p. 44) Maringá, PR.

ROCHA, Thema; GOLDSCHMIDT, Andrea. Gestão dos stakeholders. São Paulo, Saraiva, 2010.

SARASVATHY, S. D. Causation and Effectuation: Towards a theoretical shift from economic inevitability to entrepreneurial contingency. Academy of Management Review, v. 26, $\mathrm{n}^{\circ} 2$, April, 2001, p. 243-288, 2001a. 
SARASVATHY, S. D. Effectual Reasoning in Entrepreneurial Decision Making: Existence and Bounds. Best Paper Proceedings, Academy of Management. Washington, p. 3-8, 2001b.

SCHUMPETER, Joseph A. Teoria do desenvolvimento econômico, 1982.

SEBRAE, empreendedorismo, SEBRAE nacional 13 de março de 2019-. Disponível em http://m.sebrae.com.br/sites/PortalSebrae/artigos/por-que-e-fundamental-estimular-oempreendedorismo-feminino,ca96df3476959610VngVCM1000004c00210aRCRD. Acesso em 02 de Junho de 2019, as 08:00h

SEBRAE, Serviço Brasileiro de Apoio às Micro e Empresas 2013- Disponível em: http://www.noticias.sebrae.com.br/asn/2013/05/14/20489588 Acesso em: 14 de maio de 2019.

SEBRAE, Serviço Brasileiro de Apoio às Micro e Empresas 2018. PREFEITURA MUNICIPAL DE CORUMBÁ. http://www.corumba.ms.gov.br/noticias/empreendedorismofeminino-desponta-em-negocios-de-sucesso-em-corumba/22082/ acesso em 09 de junho de 2019.

SUENAGA, Camila; et al. Conceito, beleza e contemporaneidade: fragmentos históricos no decorrer da evolução estética. Itajaí: Universidade Vele do Itajaí, 2012.

TAKAHASHI, Adriana R. W. Pesquisa Qualitativa em Administração: fundamentos, métodos e usos no Brasil. São Paulo: Atlas, 2013.

VERGARA, Sylvia Constant. Métodos de Pesquisa em Administração. $5^{\text {a }}$ Ed. São Paulo: Atlas, 2012.

WORLD HEALTH ASSOCIATION. Division of Mental Health. Qualitative Research for Health Programmes. Geneva: WHA, 1994. 